\title{
Strength And Abrasion Resistance Of High Volume Fly-Ash Concrete Pavements
}

YASASVI.CHALLAPALLI M .TECH, Department of CE, MVRCET, Vijayawada, Paritala. K.PRUDHVI M.TECH , Assistant Professor , , Department of CE, MVRCET, Vijayawada, Paritala

\begin{abstract}
This paper is undertaken to evaluate the abrasion resistance and strength resistance of concrete proportioned to have five levels of cement replacements (30,35,40,45,50\%) using fly ash. A reference concrete without fly ash was proportioned to have the 28-day compressive strength of $40 \mathrm{MPa}$ are tested and the concrete specimens were subjected to abrasion according to the ASTM C- 944 te st method. In this work, all the concretes made with and without fly ash passed the abrasion resistance requirements per ASTM C-779. The fly ash makes concrete more impermeable and denser as compared to Ordinary Portland Cement. From observations the long-term strength (90 days and above) of fly ash concrete is better compared to plain concrete. The following project also gives an idea about the characteristics of skid resistance, factors affecting it and also the methods to reduce skid resistance and ultra-sonic pulse velocity test on concrete cubes and beam. The use of fly ash in concrete has received significant attention over recent years due to environmental concerns regarding its disposal and potential for use as a cementations material with its ability to provide significant benefits to concrete.
\end{abstract}

\section{Introduction}

Concrete abrasion resistance is markedly influenced by a number of factors including concrete strength, aggregate properties, surface finishing, and type of hardeners or toppings. Deterioration of concrete surfaces occurs due to various forms of wear such as erosion, cavitations, and abrasion due to various exposures.

Abrasion wear occurs due to rubbing, scraping, skidding, or sliding of objects on the concrete surface. This form of wear is observed in pavements, floors, or other surfaces on which friction forces are applied due to relative motion between the surfaces and moving objects. In general, hardened paste possesses low resistance to abrasion. In order to develop concrete for high abrasion resistance, it is desirable to use hard surface material, aggregate, and paste having low porosity and high strength. A number of investigations have shown that both surface finishing techniques and types of curing practice have a strong influence on abrasion resistance of concrete In general, hardened paste possesses low resistance to abrasion. In order to develop concrete for high abrasion resistance, it is desirable to use hard surface material, aggregate, and paste having low porosity and high strength.

Purpose of using hvfac:

Among the sustainability issues, the three major ones that are widely discussed in the published reports may be summarized as climatic change, resource productivity, and industrial ecology.

\section{Properties of Fly Ash}

It works as a water reducer, drying shrinkage,

\section{Mix Design}

Concrete must obtain a minimum compressive strength of $400 \mathrm{~kg} / \mathrm{cm} 2$ and flexural strength of 45 $\mathrm{kg} / \mathrm{cm} 2$ at 28 days. The mix should be cohesive with reasonable workability. A slump value should be range of 25 to $50 \mathrm{~mm}$ was targeted which was found to be sufficient for road work. It was envisaged to replace as much as $50 \%$ of the total cement content with good quality dry fly ash. The fly ash for the purpose was sourced from first and second fields of ESP of nearby thermal plant. Use of low water cement ratio to ensure a dense concrete with low permeability. Dosage of water reducing admixture was to be optimised to get the necessary workability at the lowest cost

\section{Methods To Improve The Skid Resistance:}

Influence of micro and macro texture:

- Composition of the wearing course must limit the binder content to designed optimum level; ensures safety and durability performance required.

- Composition of wearing course must aim at the upper limit for recommended range: reduces the tendency of bleeding due to compaction under the action of traffic and increase in temperature. 
- Composition of wearing course, the dimensions of the aggregate chips and when laying must be such that the aggregates from sufficiently sharp projections; attain a gritty surface texture

- Sand content should be increased but within limits according to ASTM

- Aggregates must be strong enough to with stand early fragmentation or wear from traffic. Compromise between providing and adequate macro-roughness and micro-roughness may be achieved by choosing a maximum grain size of $12.5 \mathrm{~mm}$.

- A composition of the wearing course must be designed to have sufficient stability; aiming at a value of stability of 5.0 reaches a compromise between the skid resistance to cracking.

\section{Surface Texture Measurement:}

- This method seeks to measure the macro texture and co relate with skid resistance.

- Road surface analyser (eg:ROSAN)

- One drawback of this method is that pavement surface macro texture does not entirely determine its skid resistance

- $\quad$ Sand patch test.

For M-40 grade the mix proportions used are

\begin{tabular}{|c|c|c|c|}
\hline Cement & Fine Aggregate & Coarse Aggregate & Water \\
\hline 1 & 1.89 & 2.48 & 0.43 \\
\hline
\end{tabular}

Tests Conducted:

1. Slump Cone Test

2. Testing Of Cubes For Compressive Strength

3. Testing Of Flexural Tensile Strength

4. Testing Of Abrasion Using Los Angeles Machine

5. Testing Of Ultra Sonic Pulse Velocity Test

6. Testing Of Skid Resistance

\section{Experimental Results:}

\begin{tabular}{|c|c|c|c|c|c|c|}
\hline Grade of Concrete & Cement (kg) & Fine Aggregate (kg) & Coarse Aggregate (kg) & Water (litres) & W/C Ratio & slump \\
\hline M40 & 430 & 816.19 & 1069.79 & 186 & 0.43 & $27 \mathrm{~mm}$ \\
\hline
\end{tabular}

\section{Compressive Strength of Concrete:}

\begin{tabular}{|c|c|c|}
\hline $\begin{array}{c}\text { Grade of concrete } \\
\text { M40 }\end{array}$ & Water-cement ratio & $\begin{array}{c}\text { Comp strength N/mm2 } \\
\text { (28 days) }\end{array}$ \\
\hline $\mathbf{0 \%}$ & $\mathbf{0 . 4 3}$ & $\mathbf{4 2 . 2}$ \\
\hline $30 \%$ & $\mathbf{0 . 4 3}$ & 39.2 \\
\hline $35 \%$ & $\mathbf{0 . 4 3}$ & 37.7 \\
\hline $40 \%$ & $\mathbf{0 . 4 3}$ & 35.6 \\
\hline $45 \%$ & $\mathbf{0 . 4 3}$ & $\mathbf{2 9 . 7}$ \\
\hline $\mathbf{5 0 \%}$ & $\mathbf{0 . 4 3}$ & $\mathbf{2 7 . 1 1}$ \\
\hline
\end{tabular}

Flexural Strength Of Concrete:

\begin{tabular}{|c|c|c|}
\hline $\begin{array}{c}\text { Grade of concrete } \\
\text { M40 }\end{array}$ & Water-cement ratio & $\begin{array}{c}\text { Flexural strength N/mm2 } \\
\text { (28 days) }\end{array}$ \\
\hline $\mathbf{0 \%}$ & $\mathbf{0 . 4 3}$ & 9 \\
\hline $30 \%$ & $\mathbf{0 . 4 3}$ & 7 \\
\hline $35 \%$ & 0.43 & 6.6 \\
\hline $40 \%$ & $\mathbf{0 . 4 3}$ & 6.48 \\
\hline $45 \%$ & $\mathbf{0 . 4 3}$ & 6.4 \\
\hline $50 \%$ & $\mathbf{0 . 4 3}$ & 6 \\
\hline
\end{tabular}

Abrasion Test Values:

\begin{tabular}{|c|c|c|}
\hline $\begin{array}{c}\text { Grade of concrete } \\
\text { M40 }\end{array}$ & Water-cement ratio & $\begin{array}{c}\text { Abrasion values in \% } \\
\text { (28 days) }\end{array}$ \\
\hline $\mathbf{0 \%}$ & $\mathbf{0 . 4 3}$ & $\mathbf{9 \%}$ \\
\hline $\mathbf{3 0 \%}$ & $\mathbf{0 . 4 3}$ & $\mathbf{8 . 5 6 \%}$ \\
\hline $\mathbf{3 5 \%}$ & $\mathbf{0 . 4 3}$ & $\mathbf{5 . 1 9 6 \%}$ \\
\hline $40 \%$ & $\mathbf{0 . 4 3}$ & $\mathbf{7 . 9 1 6 \%}$ \\
\hline $45 \%$ & $\mathbf{0 . 4 3}$ & $\mathbf{6 . 6 4 4 \%}$ \\
\hline $\mathbf{5 0 \%}$ & $\mathbf{0 . 4 3}$ & $\mathbf{8 . 4 7 8 \%}$ \\
\hline
\end{tabular}


Ultrasonic Pulse Velocity Test Values:

\begin{tabular}{|c|c|c|c|}
\hline $\begin{array}{c}\text { Grade of concrete } \\
\text { M40 }\end{array}$ & Water-cement ratio & $\begin{array}{c}\text { Upvt values m/sec cubes } \\
\text { (28 days) }\end{array}$ & $\begin{array}{c}\text { Upvt values m/sec } \\
\text { beams }\end{array}$ \\
\hline $\mathbf{0 \%}$ & $\mathbf{0 . 4 3}$ & 4636 & $\mathbf{5 0 2 8}$ \\
\hline $30 \%$ & $\mathbf{0 . 4 3}$ & 4626 & 5025 \\
\hline $35 \%$ & $\mathbf{0 . 4 3}$ & 4671 & 4912 \\
\hline $40 \%$ & $\mathbf{0 . 4 3}$ & 4479 & 4862 \\
\hline $45 \%$ & $\mathbf{0 . 4 3}$ & 4477 & 5155 \\
\hline $50 \%$ & $\mathbf{0 . 4 3}$ & 4607 & 4673 \\
\hline
\end{tabular}

Skid Resistance Test Values:

\begin{tabular}{|c|c|l|}
\hline $\begin{array}{c}\text { Grade of concrete } \\
\text { M40 }\end{array}$ & Water-cement ratio & Skid resistance in divisions \\
\hline $\mathbf{0 \%}$ & $\mathbf{0 . 4 3}$ & 35 \\
\hline $30 \%$ & $\mathbf{0 . 4 3}$ & 40 \\
\hline $35 \%$ & $\mathbf{0 . 4 3}$ & 42 \\
\hline $40 \%$ & $\mathbf{0 . 4 3}$ & 62 \\
\hline $45 \%$ & $\mathbf{0 . 4 3}$ & 39 \\
\hline $50 \%$ & $\mathbf{0 . 4 3}$ & 32 \\
\hline
\end{tabular}

\section{GRAPHS}

Compressive Strength Graph View:

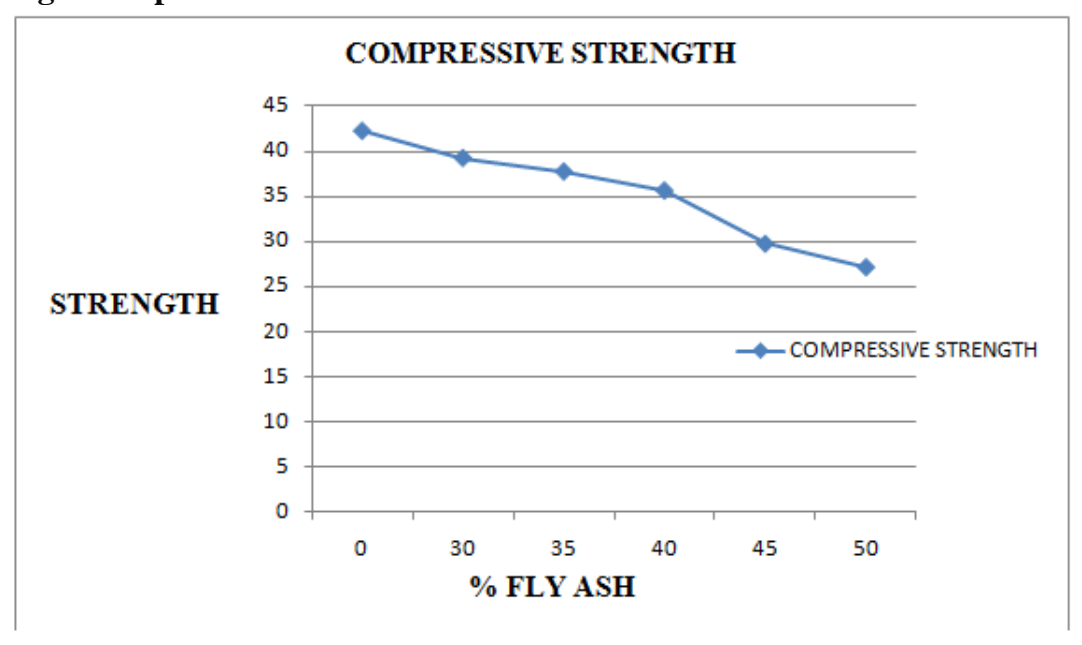

Flexural Strength Graph View:

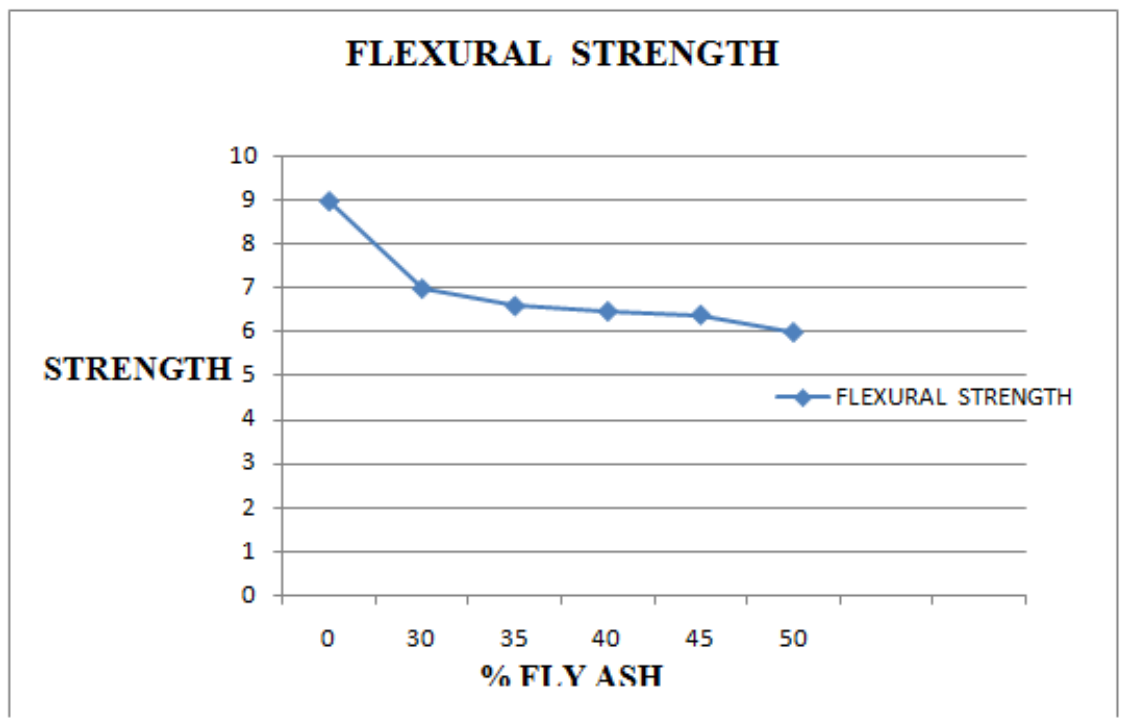

Abrasion Test Graph View: 


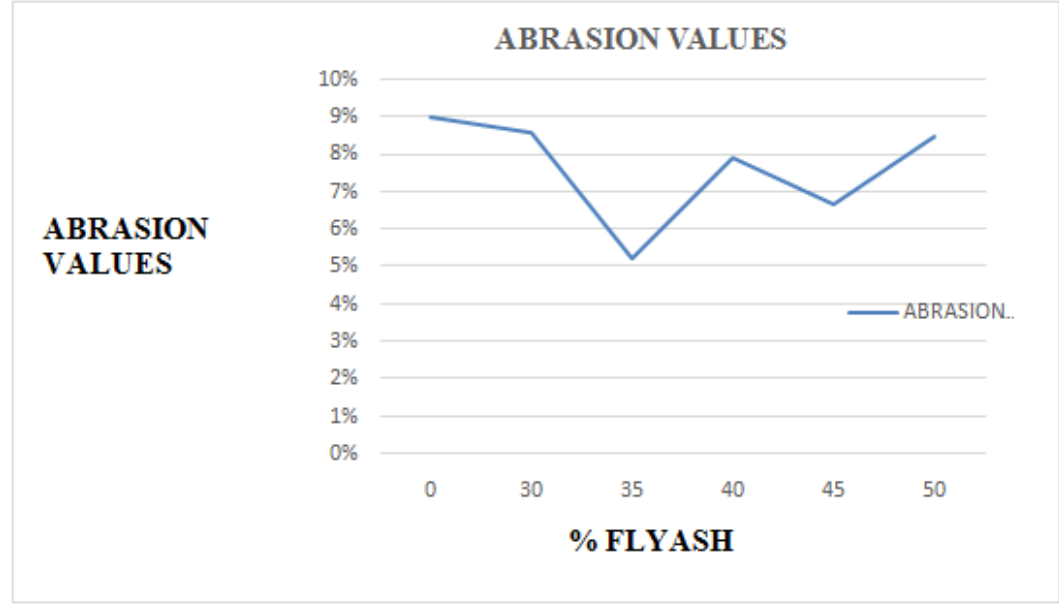

Ultrasonic Pulse Velocity Test Grapgh View:

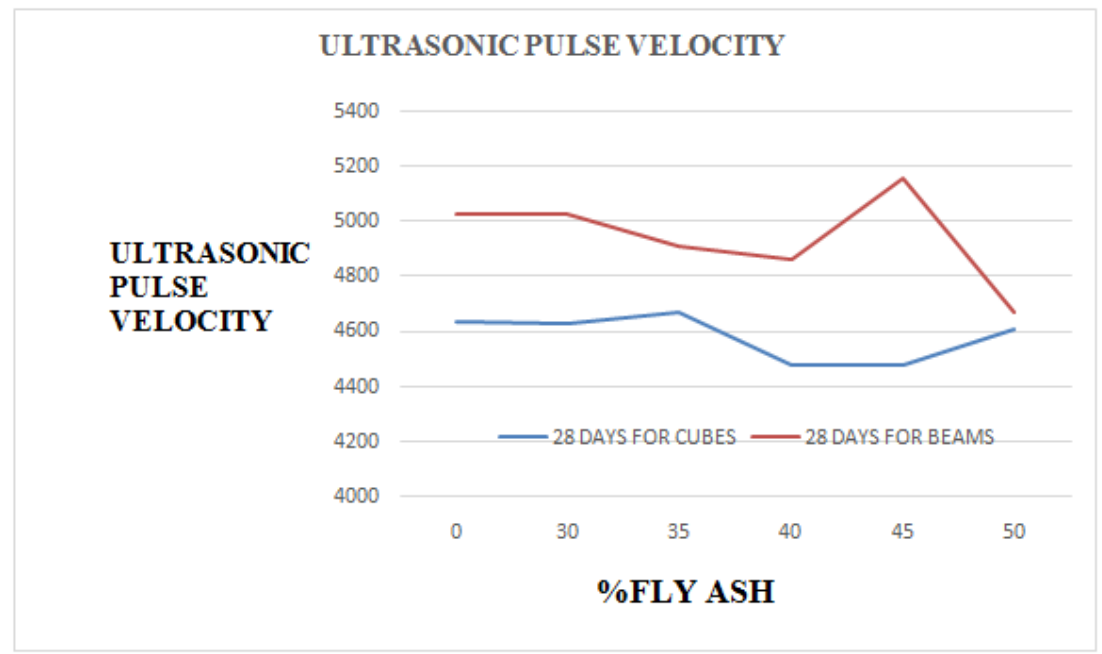

Skid Resistance Test Values Graph View:

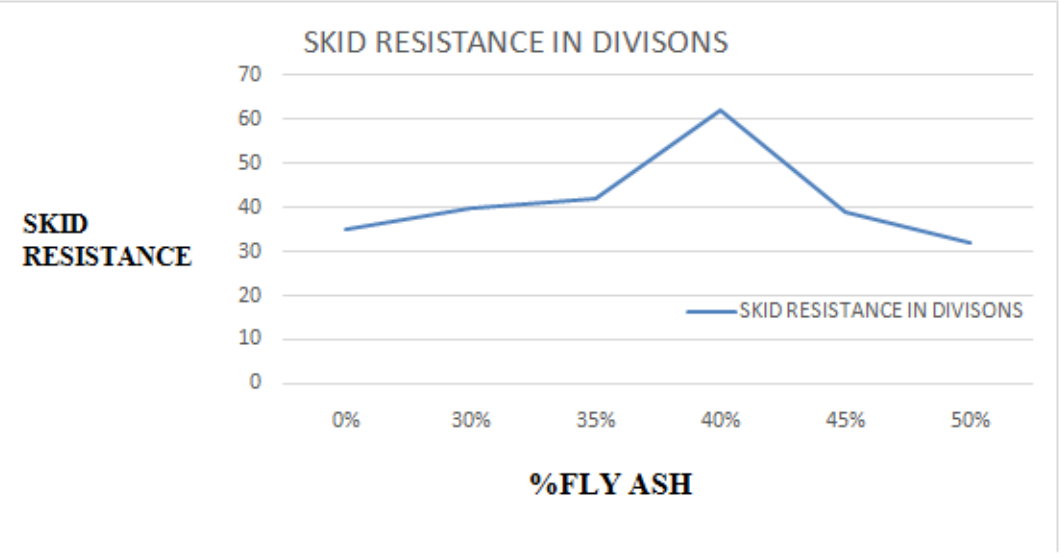

III. Conclusions

- Early age strength of concrete i.e., for 7 days \& 14 days is decreasing with increase in percentage replacement of fly ash.

- 28 days strength of concrete increasing with increase in \% replacement of fly ash up to $50 \%$.

- Flexural strength of concrete is decreasing with increase in \% replacement of fly ash. 
- Abrasion resistance of fly ash concrete with 30 to 50 percent cement replacement was lower than the no-fly ash concrete.

- By adopting above all the factors we can reduce the skidding of vehicles on concrete pavements.

- Abrasion resistance of concrete was strongly affected by its compressive strength, irrespective of fly ash content.

- Fly ash concrete up to $30 \%$ cement replacement exhibited abrasion resistance similar to the concrete without fly ash, at the 28-day, 70-day.

\section{References}

[1]. M.S. Shetty. "Concrete technology (theory and practice), S. Chand \& Company LTD. 2002

[2]. IS 10262-2009 Code of Practice for concrete Mix Proportioning-Guidelines ( $1{ }^{\text {st Revision) }}$

[3]. M.L.Gambhir. "Concrete technology (theory and practice), Fourth Edition.

[4]. IS 2386(PT7) - 1963 Methods of test for aggregates for concrete.

[5]. IS 516-1959 Method of test for strength of concrete.

[6]. IS 383-1997 used for zonation of coarse and fine aggregate.

[7]. ASTM-C597 for ultra sonic pulse velocity test.

[8]. M.S Shetty for compressive, flexural and abrasion tests.

[9]. International journal of advanced structures.

[10]. Desai,j.p "construction and performance of high volume fly ash concrete roads in india"ACI SP-221,2004

[11]. WWW.The concrete portal.com 